\title{
Simultaneous Transcriptome Analysis of Host and Pathogen Highlights the Interaction Between Brassica oleracea and Sclerotinia sclerotiorum
}

\author{
Yijuan Ding, ${ }^{1,2}$ Jiaqin Mei, ${ }^{1,2}$ Yaru Chai, ${ }^{1,2}$ Yang Yu, ${ }^{3}$ Chaoguo Shao, ${ }^{1}$ Qinan Wu, ${ }^{1}$ Joseph Onwusemu Disi, ${ }^{4}$ Yuhua Li, ${ }^{1}$ \\ Huafang Wan, ${ }^{1,2}$ and Wei Qian ${ }^{1,2, \dagger}$ \\ ${ }^{1}$ College of Agronomy and Biotechnology, Southwest University, Chongqing 400715, China; ${ }^{2}$ Academy of Agricultural Sciences, Southwest \\ University, Chongqing 400715, China; ${ }^{3}$ College of Plant Protection, Southwest University, Chongqing 400716, China; and ${ }^{4}$ Department of \\ Entomology, University of Georgia, Athens, GA 30602, U.S.A. \\ Accepted for publication 26 September 2018.
}

\begin{abstract}
White mold disease caused by Sclerotinia sclerotiorum is a devastating disease of Brassica crops. Here, we simultaneously assessed the transcriptome changes from lesions produced by $S$. sclerotiorum on disease-resistant (R) and -susceptible (S) B. oleracea pools bulked from a resistance-segregating F2 population. Virulence genes of $S$. sclerotiorum, including polygalacturonans, chitin synthase, secretory proteins, and oxalic acid biosynthesis, were significantly repressed in lesions of $\mathrm{R}$ $B$. oleracea at $12 \mathrm{~h}$ postinoculation (hpi) but exhibited similar expression patterns in R and S B. oleracea at 24 hpi. Resistant $B$. oleracea induced expression of receptors potentially to perceive Sclerotinia signals during
\end{abstract}

ABSTRACT
0 to 12 hpi and deployed complex strategies to suppress the pathogen establishment, including the quick accumulation of reactive oxygen species via activating $\mathrm{Ca}^{2+}$ signaling and suppressing pathogen oxalic acid generation in S. sclerotiorum. In addition, cell wall degradation was inhibited in the resistant $B$. oleracea potentially to prevent the expansion of Sclerotinia hyphae. The transcriptome changes in S. sclerotiorum and host revealed that resistant $B$. oleracea produces strong responses against S. sclerotiorum during early infection.

Keyword: genetics.
Sclerotinia sclerotiorum Lib. de Bary is a cosmopolitan fungal pathogen that infects $>400$ hosts, including rapeseed (Brassica napus), the third largest oilseed crop in the world (Bolton et al. 2006). The mycelium or ascospores of $S$. sclerotiorum infect the organs of rapeseed, such as flower petals, leaves, and stems, resulting in necrotic lesions, premature wilting, stem breakage, and plant lodging (Amselem et al. 2011; Garg et al. 2010). Yield losses in oilseed Brassica species vary between 5 and $100 \%$ each year (Saharan and Mehta 2008).

S. sclerotiorum secretes cell wall-degrading enzymes (e.g., pectinases, cellulases, and hemicellulases) to facilitate plant cell wall degradation, hyphae colonization, and lesion expansion (Amselem et al. 2011; Bashi et al. 2012; Li et al. 2004a, b, c; Seifbarghi et al. 2017). These processes are accompanied by the production of the nonhost-selective toxin oxalic acid (OA) to manipulate the host redox environment, which is a benefit to colonization of the host plant, suppression of host autophagy, and inhibition of plant defense responses (Cessna et al. 2000; Kabbage et al. 2013; Kim et al. 2008; Williams et al. 2011). In 2014 and 2015, a large number of secretory proteins serving as potential effectors were predicted in the genus Sclerotinia with the use of bioinformatics tools (Guyon et al. 2014; Heard et al. 2015), and

†Corresponding author: W. Qian; E-mail: qianwei666@hotmail.com

Funding: This study was financially supported by Key Projects in National Science and Technology grant 2014BAD01B07, National Nature Science Foundation of China grants 31671726 and 31801395, 973 Program grant 2015CB150201, Science and Technology Innovation Program for the Social Undertakings and the People's Livelihood in Chongqing grants cstc2016shmsx0674 and cstc2017shmsxdny80050, and Fundamental Research Funds for the Central Universities grants XDJK2018AA004 and XDJK2018B022.

Y. Ding and J. Mei contributed equally to this work.

*The $\boldsymbol{e}$-Xtra logo stands for "electronic extra" and indicates that three supplementary figures and eight supplementary tables are published online.

The author(s) declare no conflict of interest.

(C) 2019 The American Phytopathological Society several genes encoding effector have been identified (Lyu et al. 2016; Yang et al. 2018; Yu et al. 2017; Zhu et al. 2013).

In rapeseed, a number of quantitative trait loci (QTLs) and expressed sequence tags in association with resistance were identified in the partially resistant accessions, such as cultivars Zhongshuang 9 and Zhongyou 821 (Li et al. 2004a, b, c; Wu et al. 2016; Zhao et al. 2006). Several pathways and biological processes were revealed to associate with the defense against the genus Sclerotinia, such as oxidative burst, cell wall enforcement or modification, secondary metabolism and calcium binding, signaling, antioxidation, glutathione metabolism, glucosinolate metabolism, and biosynthesis of lignin (Joshi et al. 2016; Wei et al. 2016; Wu et al. 2016; Yang et al. 2007; Zhao et al. 2007, 2009). However, these studies only emphasized the response from the pathogen or the host during infection, producing an incomplete view of the interaction. For a comprehensive understanding of plant-pathogen interactions, it is valuable to analyze gene expression alterations in both pathogen and host (Kawahara et al. 2012; Westermann et al. 2012; Yazawa et al. 2013; Zhuang et al. 2012). The lack of an available host genotype with high resistance has limited the depth of understanding of the mechanistic interaction between S. sclerotiorum and its host. In 2011 and 2013, a genotype cultivar C01 of $B$. incana (a wild B. oleracea species) related to rapeseed, with nearly 20 -fold higher stem resistance than partially resistant B. napus cultivar Zhongyou 821, was identified, and resistance QTLs were mapped in a resistance segregation population derived from a cross between $\mathrm{C} 01$ and a susceptible B. oleracea (Mei et al. 2011 , 2013). In this study, the stems of extreme disease-resistant (R) and -susceptible (S) lines in this segregation population were inoculated with the genus Sclerotinia, and the transcriptome changes in both host and pathogen in lesions were analyzed. Our data suggested that the $\mathrm{R} B$. oleracea quickly perceives $S$. sclerotiorum secretory proteins or/and pathogen-associated molecular pattern (PAMPs), limits the expression of virulence genes, and quickly accumulates reactive oxygen series (ROS) to inhibit the $S$. sclerotiorum establishment by activating $\mathrm{Ca}^{2+}$ signaling and suppressing pathogen OA generation. Meanwhile, 
the gene expressions of pectin methylesterase inhibitors (PMEIs) and pectinesterase inhibitors (PEIs) in R B. oleracea were promoted to suppress the cell wall degradation and prevent hyphae expansion. This study expands our understanding of the interaction between the genus Brassica and S. sclerotiorum.

\section{MATERIALS AND METHODS}

Plant materials and inoculation of the genus Sclerotinia. In a previous study (Mei et al. 2013), the stem resistance against $S$. sclerotiorum was investigated in an F2 population composed of 149 vegetative cloned lines derived from the cross between a resistant genotype $\mathrm{C} 01$ (B. incana) and a susceptible genotype cultivar C41 (B. oleracea var. alboglabra). Based on the resistance evaluation, four extreme resistant F2 cloned lines were chosen together with $\mathrm{C} 01$ as the $\mathrm{R}$ group, whereas four highly susceptible F2 cloned lines and the susceptible parent $\mathrm{C} 41$ formed the $\mathrm{S}$ group. Plants were grown in the growth chamber at $22^{\circ} \mathrm{C}$ in the light (fluorescent lamp, $100 \mathrm{lux}$ ) and $16^{\circ} \mathrm{C}$ in the dark. At the end of flowering, for each time point, three plants in each line were inoculated with 6-mm mycelia plugs obtained from actively growing colony edges of $S$. sclerotiorum '1980' grown on the potato dextrose agar medium ( $20 \%$ potato, $2 \%$ dextrose, and $1.5 \%$ agar). Three sites on the main stem of each plant were inoculated and secured with Parafilm. The infection temperature was maintained at $22^{\circ} \mathrm{C}$ under $85 \%$ humidity. The epidermal stem tissues composed of the symptomatic lesion and the $10-\mathrm{mm}$ region extending beyond the lesion margin were excised at 0,12 , and $24 \mathrm{~h}$ postinoculation (hpi) for total RNA extraction with the RNAprep pure Plant Kit (DP 432; Tiangen Biotech [Beijing] Co., Ltd.). RNA was bulked separately at each time point within the $\mathrm{R}$ and $\mathrm{S}$ groups (yielding six samples encoded with R0, R12, R24, S0, S12, and S24) and sequenced with three biological replicates.

RNA sequencing and data analysis. The sequencing library was generated using the NEBNext Ultra RNA Library Prep Kit for Illumina (NEB, USA) following the manufacturer's recommendation and sequenced on an Illumina Hiseq 2000 platform, which yields $100-b p$ paired end reads. The raw reads were filtered to obtain high-quality clean reads by removing adaptor sequences, duplicated sequences, reads containing $>5 \%$ " $\mathrm{N}$ " (i.e., ambiguous bases in reads), and reads in which $>50 \%$ of the bases showed a $Q$ value (i.e., Bonferroni-adjusted $P$ value) $\leq 5$. Clean reads were aligned to the reference genome of B. oleracea (http://brassicadb.org/ brad/downloadOverview.php) and S. sclerotiorum (http://fungidb. org/common/downloads/Current_Release/Ssclerotiorum1980UF70/) by using the TopHat program (http://ccb.jhu.edu/software/ tophat/index.shtml) with default parameters, except that the $Q$ value was set to 100 . Gene expression was quantified using htseq-count 0.6.1p2 (http://www-huber.embl.de/users/anders/HTSeq/doc/count. html). The raw counts were normalized by TMM (the weighted trimmed mean of M-values) normalization using the edgeR package (Robinson et al. 2010), and the differential expression analysis was carried out using the DEGseq package (Wang et al. 2010). The threshold determining the significance of differentially expressed genes (DEGs) among multiple tests was set at a false discovery rate $($ FDR $) \leq 0.001$ and $\mid \log _{2}$ ratio $\mid \geq 1$ (Mao et al. 2018). GO and KEGG enrichment analyses were performed with an FDR $\leq 0.05$ as the threshold using BiNGO (Maere et al. 2005) and KOBAS 3.0 (http://kobas.cbi.pku.edu.cn/), respectively.

Validation of the RNA-seq. Quantitative reverse transcription polymerase chain reaction (qRT-PCR) analysis was performed to test the gene expression in three replications with iTaq Universal SYBR Green Supermix (Bio-Rad) in the CFX96 Real-Time PCR Detection System. The polymerase chain reaction cycling conditions included 1 cycle of $95^{\circ} \mathrm{C}$ for $30 \mathrm{~s}$ and then 39 cycles of $95^{\circ} \mathrm{C}$ for $5 \mathrm{~s}$ and $55^{\circ} \mathrm{C}$ to $70^{\circ} \mathrm{C}$ for 1 min followed by a melting curve ramping from $65^{\circ} \mathrm{C}$ to $95^{\circ} \mathrm{C}$, with temperature increasing by $0.5^{\circ} \mathrm{C}$ every $5 \mathrm{~s}(1 \mathrm{cycle})$. The genes BoActin 3 and SsTubulin were used as the internal controls for the expression analyses of $20 \mathrm{~B}$. oleracea and $15 \mathrm{~S}$. sclerotiorum DEGs, respectively. The primers for qRT-PCR are listed in Supplementary Table S1. Pearson's simple correlation coefficients were calculated among the results of qRT-PCR and RNA-seq.

Identification of pathogen secretory proteins. To identify the differentially expressed pathogen secretory proteins, the sequences of DEGs in $S$. sclerotiorum were first screened by SignalP 4.1 (http://www.cbs.dtu.dk/services/SignalP/) in default settings for signal peptide cleavage sites (Nielsen 2017), and then, we screened the transmembrane domains with TMHMM (http:// www.cbs.dtu.dk/services/TMHMM/) (Möller et al. 2001). Proteinencoding signal peptides but no transmembrane domains were considered candidate secretory proteins (Lum and Min 2011).

Hydrogen peroxide staining. To detect hydrogen peroxide $\left(\mathrm{H}_{2} \mathrm{O}_{2}\right)$ accumulation in situ, inoculated stems of extreme $\mathrm{R}$ and $\mathrm{S}$ $B$. incana $\times$ B. oleracea var. alboglabra $\mathrm{F} 2$ lines were stained with 3'3'-diaminobenzidine (DAB; Sigma-Aldrich; $1 \mathrm{mg} / \mathrm{ml}$ DAB-HCl, $\mathrm{pH}$ 7.4) under a gentle vacuum for $5 \mathrm{~h}$ and then washed three times in distilled water.

Resistance assay of homologous Arabidopsis mutant. The homologous Arabidopsis T-DNA (Transfer DNA) mutants, AT3G47380.1: SALK_015169C (homologous to Bol023155 [PMEI]) and AT3G58790.1: SALK_137818C (homologous to Bol044481 [GAUT15]), were acquired from the Arabidopsis Biological Resource Center at The Ohio State University. The pathogenicity assays with three replicates were conducted as described by Wang et al. (2015) with minor modifications. Briefly, five leaves at 3 weeks old of every line were inoculated with a 2-mm mycelia plug obtained from actively growing colony edges of $S$. sclerotiorum '1980'. The lengths and widths of lesions were measured with a caliper at $24 \mathrm{hpi}$, and the lesion size $(S=\pi \times$ length $\times$ width/4) was calculated.

\section{RESULTS}

Phenotypic variances and general transcriptome changes in pathogen and host. Based on 2 years of evaluation of stem resistance (Mei et al. 2013), cloned lines with extreme resistance were chosen in the F2 population and reevaluated in the other

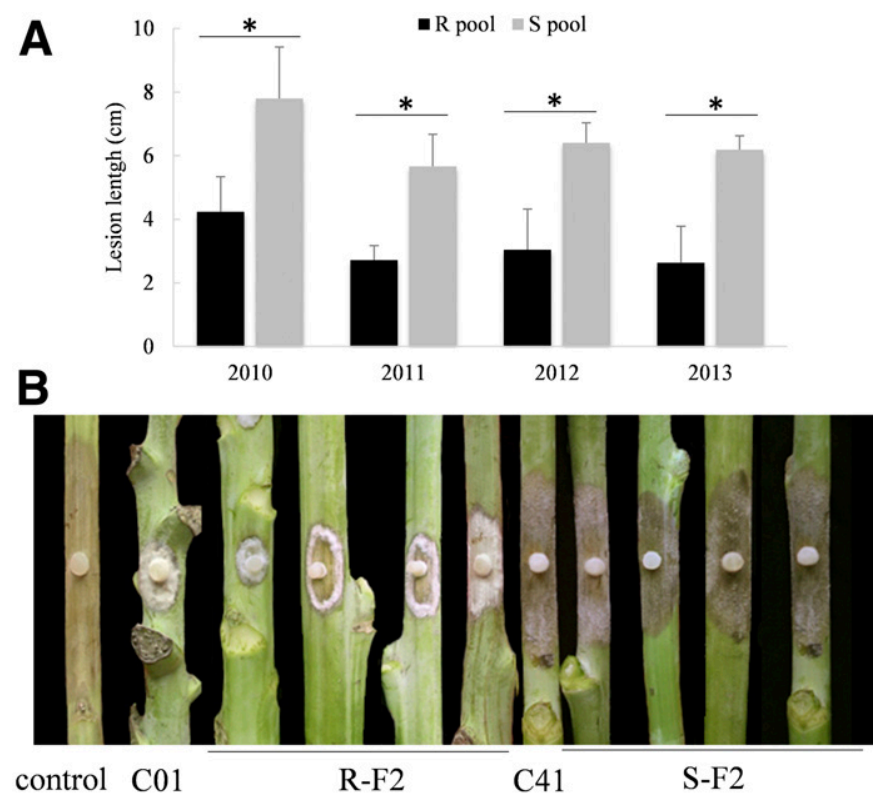

Fig. 1. Resistance against Sclerotinia sclerotiorum in disease-resistant $(\mathrm{R})$ and -susceptible (S) Brassica oleracea groups. A, Lesion size of $\mathrm{R}$ and $\mathrm{S}$ of $B$. oleracea $72 \mathrm{~h}$ postinoculation (hpi) across 4 years. B, Symptom of infection by $S$. sclerotiorum among $\mathrm{R}$ and $\mathrm{S}$ plants in B. oleracea at $72 \mathrm{hpi}$. The control, cultivar Zhongshuang 9, is a partially resistant rapeseed variety against $S$. sclerotiorum. * represents significant difference was detected between the $\mathrm{R}$ and S pool ( $* P<0.05$, Student's $t$ test). 
2 years. A total of 4 years of resistance data revealed a significant difference for the lesion size between the $\mathrm{R}$ and $\mathrm{S} B$. olerace a groups (Fig. 1). The lesion lengths of the $\mathrm{R}$ and $\mathrm{S} B$. oleracea groups averaged $2.45 \mathrm{~cm}(1.75$ to $2.90 \mathrm{~cm})$ and $5.50 \mathrm{~cm}(4.95$ to $6.11 \mathrm{~cm})$ at 72 hpi, respectively.

The cDNA (complementary DNA) libraries of six samples (R0, $\mathrm{R} 12$, R24, S0, S12, and S24) with three biological replicates were sequenced on the Illumina Hiseq 2000 platform and produced an average of 48.2 million clean reads for each sample (Table 1). Among these, 2.5 million mean clean reads per sample mapped to the reference genome of $S$. sclerotiorum, covering $73.8 \%$ (10,706 of 14,509 ) of the $S$. sclerotiorum genes except for R0 and S0, where $<0.01 \%$ clean reads mapped to the $S$. sclerotiorum reference genome; 37 million mean clean reads per sample were mapped to the reference genome of $B$. oleracea, covering $77.1 \%(35,262$ of 45,759 ) of the $B$. oleracea genes on average (Table 1). To validate the data obtained by RNA-seq, we performed qRT-PCR analyses by choosing $15 \mathrm{~S}$. sclerotiorum genes and $20 \mathrm{~B}$. oleracea genes of interest and confirmed that the expression obtained from qRT-PCR and RNA-seq was highly consistent $(R=0.899, P<0.01)$ (Supplementary Fig. S1).
We detected 326 DEGs of $S$. sclerotiorum from lesions between $\mathrm{R}$ and S B. oleracea at 12 hpi (Ss-DEGs-12) and 582 Ss-DEGs-24 (Fig. 2A). The GO biological processes "carbohydrate metabolic process," "oxalate metabolic process," and "pectin catabolic process" and the KEGG pathways "ribosome" and "pentose and glucuronate interconversions" were specifically enriched in Ss-DEGs-12, whereas Ss-DEGs-24 were significantly enriched in "response to oxygencontaining compound," "translation," and "ribosome" (Fig. 2B).

A total of 1,768 and 2,882 DEGs of B. oleracea (Bol-DEGs) in the R B. oleracea and 4,130 and 2,335 Bol-DEGs in the $\mathrm{S}$ B. olerace $a$ were found during 0 to 12 and 12 to $24 \mathrm{hpi}$, respectively. Common responses between the $\mathrm{R}$ and $\mathrm{S} B$. oleracea involved several GO biological processes, such as "response to hormone," "salicylic acid/jasmonic acid mediated signaling pathway," "defense response," "immune response," "response to fungus," "response to chitin," "Mitogen-activated protein kinase (MAPK) cascade," and "systemic acquired resistance," and several KEGG pathways, such as "photosynthesis," "biosynthesis of secondary metabolites," "circadian rhythm," "plant-pathogen interaction," "photosynthesis-antenna proteins," "flavonoid biosynthesis," and "plant hormone signal transduction" (Supplementary Fig. S2).

TABLE 1. Summary of sequence read alignments to the reference genomes of Brassica oleracea and Sclerotinia sclerotiorum averages by three biological replicates

\begin{tabular}{|c|c|c|c|c|c|c|}
\hline \multirow[b]{2}{*}{ Sample } & \multicolumn{6}{|c|}{ Sample name } \\
\hline & R0 & $\mathrm{R} 12$ & R24 & S0 & $\mathrm{S} 12$ & S24 \\
\hline Clean reads & $43,151,218$ & $71,681,872$ & $50,330,142$ & $43,863,880$ & $41,783,110$ & $38,286,552$ \\
\hline $\begin{array}{l}\text { Uniquely mapped to } B \text {. } \\
\text { oleracea }\end{array}$ & $33,711,070(78.1 \%)$ & $54,163,249(75.6 \%)$ & $36,979,413(73.5 \%)$ & $34,792,774(79.3 \%)$ & $29,863,996(71.5 \%)$ & $26,226,279(68.5 \%)$ \\
\hline $\begin{array}{l}\text { Total mapped to } S . \\
\text { sclerotiorum }\end{array}$ & $1,741(0.004 \%)$ & $2,524,946(3.5 \%)$ & $3,522,380(7 \%)$ & $3,520(0.007 \%)$ & $3,832,964(9.2 \%)$ & $4,843,058(12.7 \%)$ \\
\hline
\end{tabular}

A

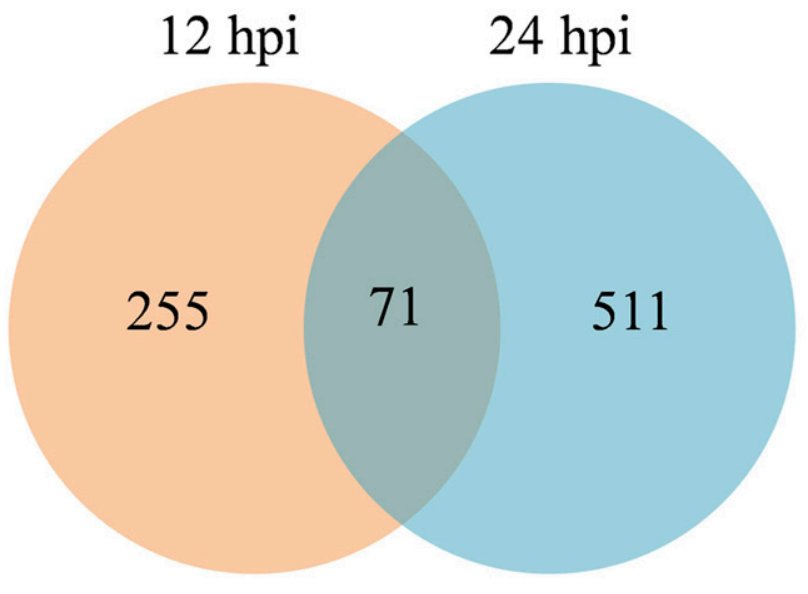

B

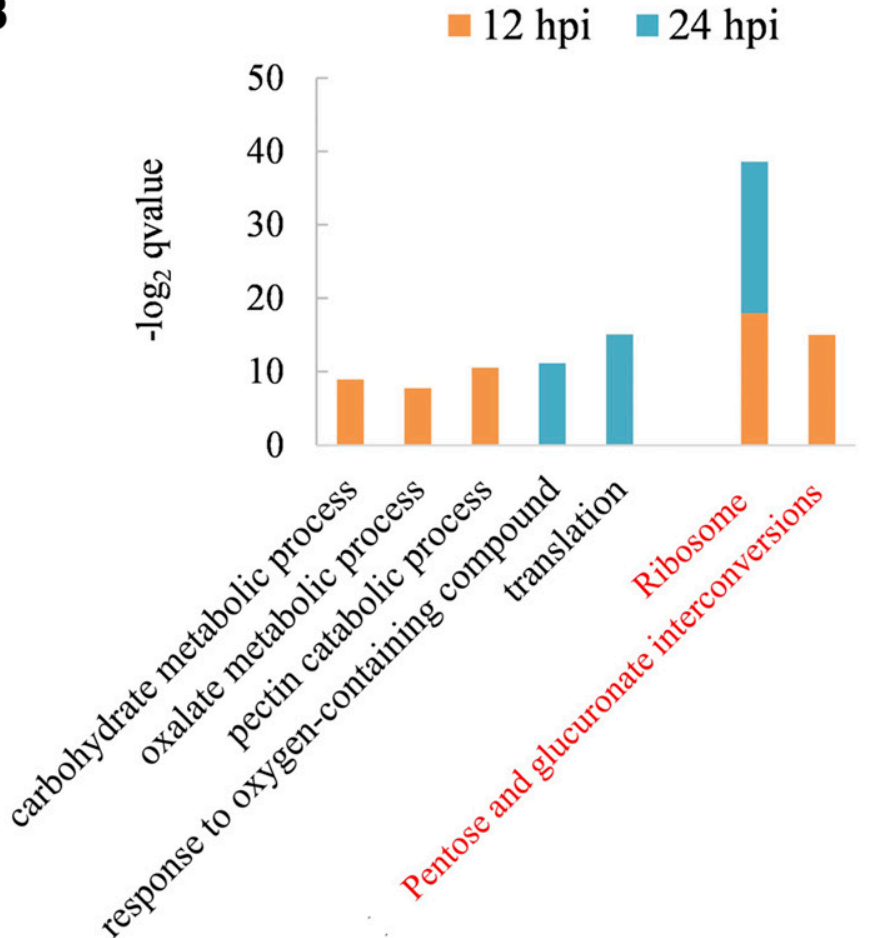

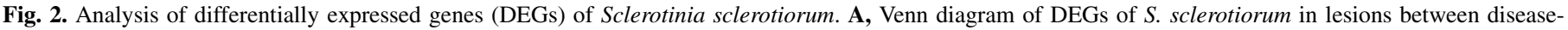

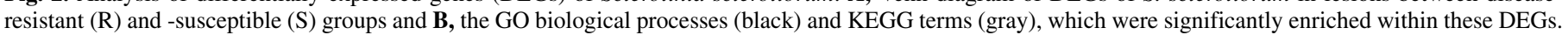


Nevertheless, specific DEGs analysis revealed different responses between the $\mathrm{R}$ and $\mathrm{S}$ B. oleracea involved in the biological process "cell wall organization or biogenesis" and the pathways "plantpathogen interaction," "pentose and glucuronate interconversions," "starch and sucrose metabolism," and "regulation of autophagy" (Fig. 3).

Interaction between pathogen and host. The KEGG pathway "Plant-pathogen interaction" (ko04626) was significantly enriched in both R-specific up-regulated DEGs and S-specific down-regulated DEGs of B. oleracea during 0 to 12 hpi (Fig. 3). Specific categories included pathogen perception, $\mathrm{Ca}^{2+}$ signaling, MAPK-WRKY signaling, ROS activation, and disease resistance proteins. Host perception of pathogen-secreted proteins and PAMPs may determine infection success after infection (Dangl et al. 2013; Wirthmueller et al. 2013). A total of 93 Ss-DEGs encoding the protein with signal peptides, but no transmembrane domains were regarded as the candidate genes of secretory proteins (Supplementary Table S2). Of these, 83 genes exhibited higher expression in lesion of S B. oleracea than R B. oleracea, whereas 10 genes had the same expression level in R and S B. oleracea at $12 \mathrm{hpi}$. Additionally, all 93 genes exhibited the same expression levels in $\mathrm{R}$ and $\mathrm{S}$ $B$. oleracea at 24 hpi. It seems to indicate that these 83 candidate secretory proteins may be involved in the virulence of $S$. sclerotiorum, especially in the early infection.

Chitin is an important component of fungal cell wall, and it is regarded as a PAMP (Yamaguchi et al. 2017). Chitin synthase is associated with virulence of $S$. sclerotiorum (Andrade et al. 2016). We detected 11 chitin synthase genes with higher expression level in lesion of S B. oleracea than R B. oleracea at 12 hpi and without expression difference between $\mathrm{R}$ and $\mathrm{S}$ B. oleracea at $24 \mathrm{hpi}$. It suggests that the expression of chitin synthase genes is limited in $\mathrm{R}$ B. oleracea during 0 to 12 hpi.

Proteins with the domain of leucine-rich repeat (LRR), LRR kinase, lectin kinase, serine/threonine kinase, or LysM domaincontaining GPI-anchored protein 2 precursor (LysM2) are regarded as candidate receptors to perceive pathogen effectors and PAMPs during early infection (Dangl et al. 2013). A total of 51 Bol-DEGs in $B$. oleracea were identified as candidate receptor genes, including 22 DEGs specifically induced in $\mathrm{R} B$. olerace a during 0 to $12 \mathrm{hpi}$ and 29 DEGs with the same expression pattern in both $\mathrm{R}$ and $\mathrm{S}$ B. oleracea (Supplementary Table S3). Specifically, two receptor genes (Bol036654 and Bol021625) showed higher up-regulated expression of around threefold in R B. oleracea as revealed by qRTPCR but no changes in S B. oleracea during 0 to 12 hpi. We further investigated the expression of these two receptors in the parental B. oleracea lines. Both Bol036654 and Bol021625 were upregulated in the $\mathrm{R}$ parental line, but there were no changes in the $\mathrm{S}$ parental line at 9 hpi (Supplementary Fig. S3). These findings potentially indicate an effective perception of $S$. sclerotiorum by the $\mathrm{R}$ B. oleracea. It was in accordance with the observation of a delay of infection establishment in R B. oleracea. Among 11 compound appressorium-associated Sclerotinia DEGs detected, 8 exhibited lower expression at 12 hpi in lesion of $\mathrm{R} \mathrm{B}$. oleracea than $\mathrm{S}$ B. oleracea (Fig. 4A; Supplementary Table S4). Furthermore, the observation of scanning electron microscopy revealed that the infection cushions were successfully established in S B. oleracea at 9 hpi but not in R B. oleracea, and there were more and larger infection cushions in $\mathrm{S}$ B. oleracea than in R B. oleracea at $12 \mathrm{hpi}$ (Fig. 4B).

Transient elevation of cytosolic $\mathrm{Ca}^{2+}$ occurs after pathogen perception to activate downstream signaling cascades (Takahashi et al. 2011; Tena et al. 2011). A total of 45 B. oleracea genes involved in the $\mathrm{Ca}^{2+}$ signaling showed differential expression patterns between R and S B. oleracea during 0 to $12 \mathrm{hpi}$. Among them, 28 DEGs were up-regulated in the R B. oleracea but stably expressed (24 genes) or down-regulated (4 genes) in the $\mathrm{S}$ B. oleracea, whereas the other 17 DEGs were stably expressed in the R B. oleracea but down-regulated (15 genes) or up-regulated
(2 genes) in the $\mathrm{S}$ B. oleracea, indicating a stronger $\mathrm{Ca}^{2+}$ signaling in the $\mathrm{R} B$. oleracea in early infection. This was in accordance with the qRT-PCR analysis in R and S parental lines. For example, calciumdependent protein kinase 6 (Bol042113) showed up-regulated expression at 6 hpi (4.5-fold) and 9 hpi (6.6-fold) in the R parental line but was not significantly induced in the $S$ parental line.

Plant $\mathrm{Ca}^{2+}$ signaling regulates the generation of ROS by modulating the activity of respiratory burst oxidase homologs $(R B O H s)$ (Arthikala et al. 2014; Keller et al. 1998; Li et al. 2015). Four differentially expressed RBOHF genes (Bol022639, Bol000420, Bol033122, and Bol043072) detected during 0 to $12 \mathrm{hpi}$ exhibited a higher levels of up-regulated expressions in the $\mathrm{R} B$. oleracea than in the $\mathrm{S} B$. oleracea. We chose an $R B O H$ (Bol022639) for qRT-PCR analysis in R and S parental lines and found that it showed up-regulated expression at $9 \mathrm{hpi}$ of 2.88 -fold in the $\mathrm{R}$ but that it was not significantly induced in the $\mathrm{S}$ parental line from 6 to 9 hpi. These findings seem to indicate increased production of ROS in R B. oleracea than in S B. oleracea during early infection. This speculation was confirmed by DAB staining, which showed an earlier accumulation of $\mathrm{H}_{2} \mathrm{O}_{2}$ in the $\mathrm{R}$ than in the L lines (Fig. 5).

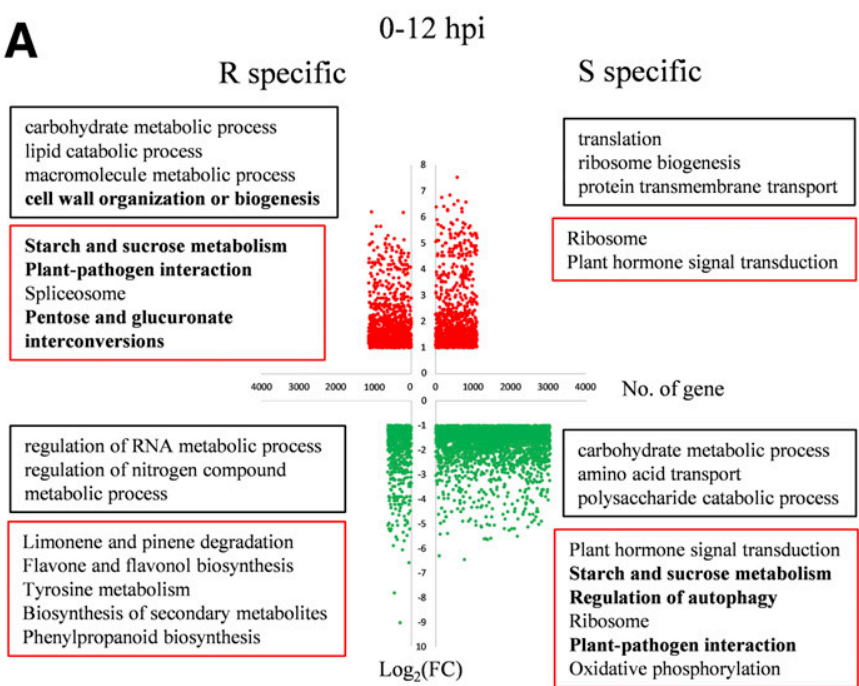

B

\section{2-24 hpi}

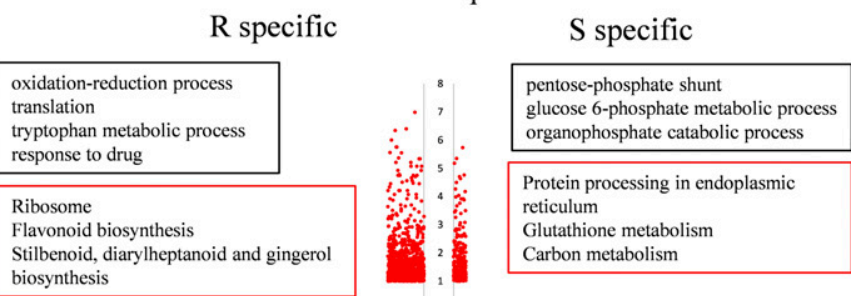

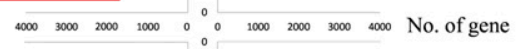

\begin{tabular}{|l|}
\hline $\begin{array}{l}\text { protein modification process } \\
\text { carbohydrate biosynthetic process }\end{array}$ \\
\hline Ribosome \\
Plant hormone signal transduction \\
Plant-pathogen interaction \\
Starch and sucrose metabolism \\
Carbon metabolism \\
Pentose and glucuronate \\
interconversions \\
\hline
\end{tabular}

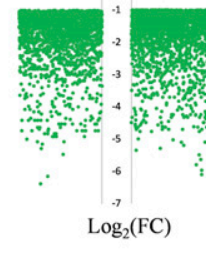

pentose metabolic process L-arabinose metabolic process cell death

Ribosome Plant hormone signal transduction Plant-pathogen interaction $\mathrm{ABC}$ transporters

Fig. 3. Analysis of specific differentially expressed genes (DEGs) between disease-resistant (R) and -susceptible (S) Brassica oleracea. GO biological processes in black boxes and KEGG terms in red boxes were significantly enriched with specific DEGs between $\mathrm{R}$ and $\mathrm{S}$ B. oleracea groups during the $\mathbf{A}$, early (0 to $12 \mathrm{~h}$ postinoculation [hpi]) and $\mathbf{B}$, late (12 to $24 \mathrm{hpi}$ ) infection against Sclerotinia sclerotiorum. $\mathrm{FC}=$ fold change. 
Cell wall changes in the host. The host cell wall is a physical defense against pathogens. A total of 66 Ss-DEGs were enriched into GO and KEGG terms related to cell wall degradation, such as "carbohydrate metabolic," "pectin catabolic," and "pentose and glucuronate interconversions" (Fig. 2), including 30 carbohydrateactive enzymes and auxiliary proteins (CAZymes) involved in the degradation of plant cellulose (5 genes), hemicellulose (10 genes), and pectin (15 genes) (Supplementary Table S5). Of these, 27 CAZymes showed lower expression in the lesion of $\mathrm{R} B$. oleracea than in S B. oleracea at $12 \mathrm{hpi}$, whereas 3 CAZymes exhibited a similar expression pattern in $\mathrm{R}$ and $\mathrm{S} B$. oleracea. It seems to indicate that the expressions of pathogen cell wall degradation enzymes were suppressed when infecting the $\mathrm{R} B$. oleracea.

Correspondingly, a total of 314 Bol-DEGs involved in the cell well metabolism were enriched in the GO term "cell wall organization or biogenesis" (66 genes) and the KEGG terms "pentose and glucuronate interconversions" (125 genes) and "starch and sucrose metabolism" (232 genes) (Fig. 3), with 49 overlapping DEGs among the three terms (Supplementary Table S6). Those 49 DEGs were specifically induced in $\mathrm{R} B$. oleracea but not in $\mathrm{S}$ $B$. oleracea during 0 to $12 \mathrm{hpi}$, including eight $P M E I$ s and seven $P E I$, which inhibit the catalyzation of plant cell wall polygalacturonans (Lionetti et al. 2012). The Bol023155 (PMEI) showed the highest up-regulated expression at 210 -fold in $\mathrm{R}$ B. oleracea during 0 to 12 hpi. In addition, the expressions of three galacturonosyltransferases (GAUT14, GAUT15, and GATL8), which are key enzymes in pectin biosynthesis, and one cellulose synthase-like protein (CSLD2) were detected specifically up-regulated in $\mathrm{R}$ B. oleracea. The Arabidopsis T-DNA mutants homologous to Bol023155 (PMEI) and Bol044481 (GAUT15) were evaluated for the genus Sclerotinia resistance. Both mutant lines showed enhanced susceptibility to $S$. sclerotiorum in comparison with the wild-type Col-0 (Columbia-0) (Fig. 6). These findings indicate that $\mathrm{R} B$. oleracea genotypes inhibit lesion expansion by possibly inhibiting cell wall decomposition and promoting the cell wall reorganization or rearrangement.
OA. S. sclerotiorum pathogenesis accumulates high levels of OA during the successful establishment of colonization in the host and modulates the host redox environment to block the host oxidative burst (Kabbage et al. 2013; Williams et al. 2011). The activation of oxaloacetate acetylhydrolase (SSOAH; SS1G_08218) is required in the final step of OA biosynthesis, which is regulated by the zinc finger transcription factor SSPAC1 (SS1G_07355) (Liang et al. 2015a, 2015b; Rollins 2003). We found that both $S S O A H$ (Fig. 7; Supplementary Table S7) and SsPACl (Fig. 7) exhibited lower expressions at $12 \mathrm{hpi}$ in lesions of $\mathrm{R} B$. oleracea than in $\mathrm{S}$ $B$. oleracea but similar expressions at 24 hpi in the two groups. The oxalate decarboxylase (SsODC2; SS1G_10796) (Liang et al. 2015a, 2015b) exhibited similar expression in lesions of $\mathrm{R}$ and S B. oleracea at 12 hpi but higher expression at 24 hpi in $\mathrm{R}$ B. oleracea than in $\mathrm{S} B$. oleracea.

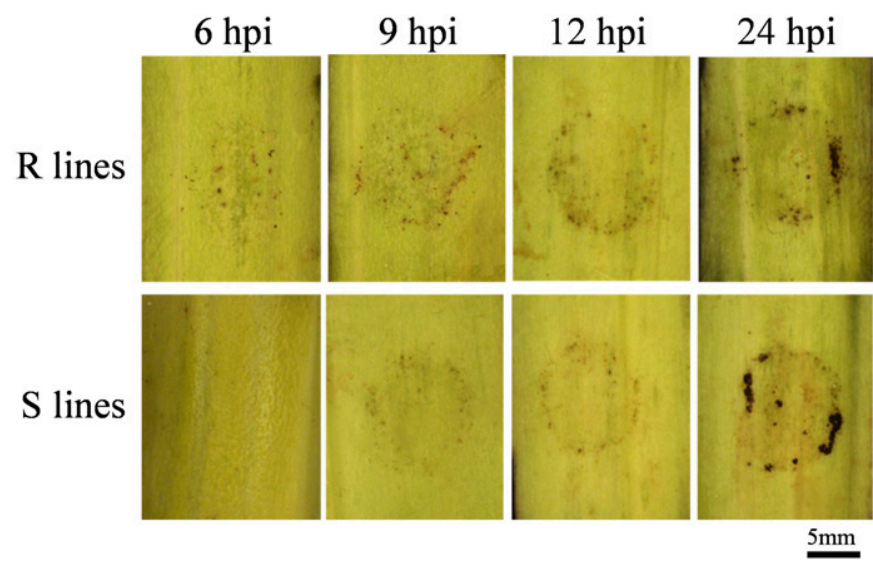

Fig. 5. Hydrogen peroxide accumulation in extreme disease-resistant (R) and -susceptible (S) Brassica incana $\times$ B. oleracea var. alboglabra F2 lines after inoculation of Sclerotinia sclerotiorum. hpi = hours postinoculation.

\section{A appressorium-associated genes B}

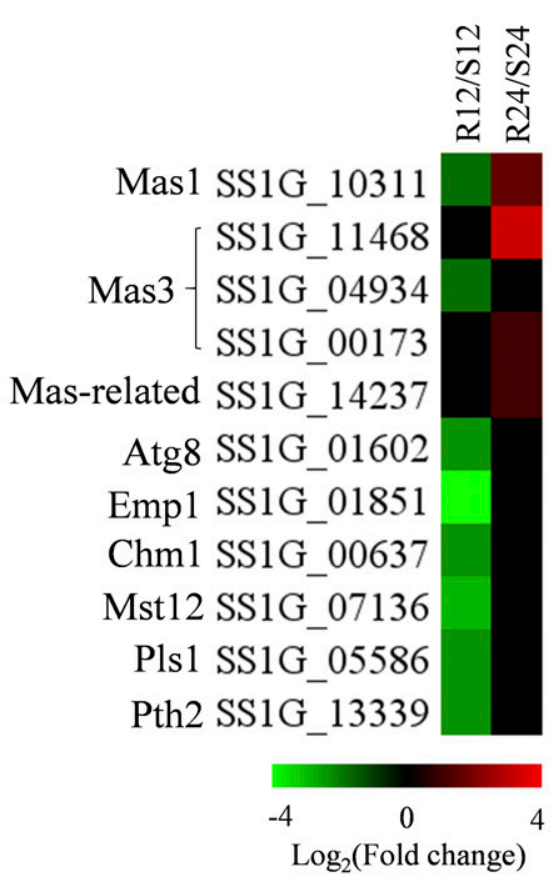

$\mathrm{R}$ lines
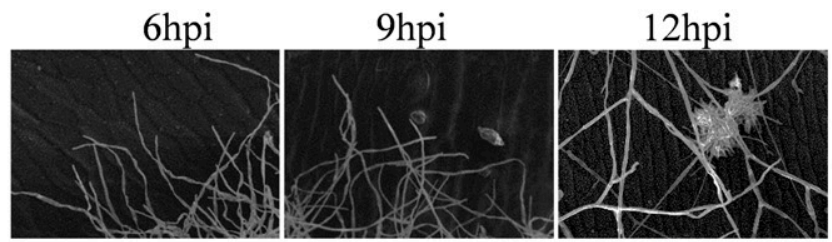

S lines
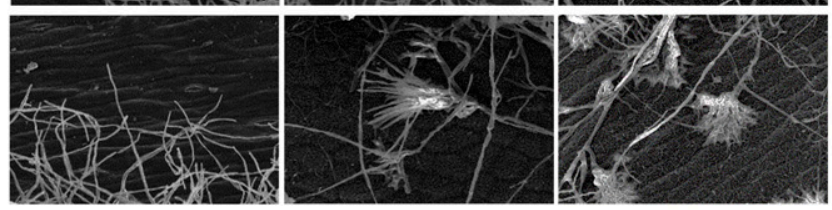

$200 \mu \mathrm{m}$

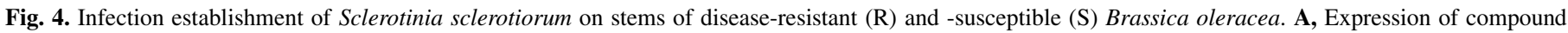

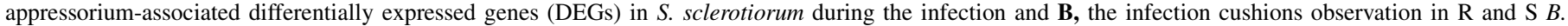
olerace a at 6,9 , and $12 \mathrm{~h}$ postinoculation (hpi) revealed by electron microscopy. 
Pathogen OA is reported to suppress host autophagy (Kabbage et al. 2013). We found that the pathway "regulation of autophagy" was significantly enriched in S B. oleracea but not in R B. oleracea during 0 to 12 hpi with 19 specific down-regulated DEGs, including 8 ATG 8 and 1 ATG3 (Fig. 7; Supplementary Table S8), which are the key genes to modulate plant autophagy (Bassham et al. 2006; Kabbage et al. 2013). It suggests that the autophagy pathway is significantly suppressed in S B. oleracea in the early infection.

\section{DISCUSSION}

In this study, the interaction between the genus Brassica and the genus Sclerotinia was revealed by simultaneously investigating the transcriptome changes in $S$. sclerotiorum and $\mathrm{R}$ and $\mathrm{S} B$. oleracea. In comparison with the $\mathrm{S} B$. oleracea, the $\mathrm{R} B$. oleracea seems to have a stronger ability to defend Sclerotinia inoculation by

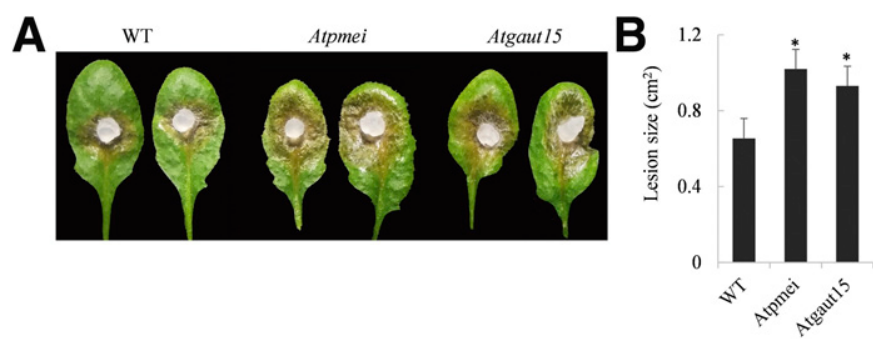

Fig. 6. Resistance assay of Arabidopsis mutants homologous to BolPMEI and BolGAUT15. Agar plugs containing actively growing cultures of the wild-type (WT) strain cultivar 1980 of Sclerotinia sclerotiorum were inoculated onto leaves of Arabidopsis WT (Columbia-0) and select Arabidopsis PMEI (Atpmei: homologous to Bol023155) and GAUT15 (Atgaut15: homologous to Bol044481) mutant plants. A, The lesion phenotype at $24 \mathrm{~h}$ postinoculation (hpi), and $\mathbf{B}$, lesion size was monitored from three biological replicates. *Significant difference at $P<0.05$ (two-tailed $t$ test). hindering the expression of Sclerotinia virulence genes, such as genes encoding secretory proteins PAMPs and CAZymes, blocking appressorium establishment, and causing an earlier oxidative burst at the inoculate site. Meanwhile, the degradation of the plant cell wall was suppressed and autophagy was maintained in $\mathrm{R}$ B. oleracea.

The initiation of plant defense against a pathogen starts with the perception of pathogen effectors or PAMPs (Wirthmueller et al. 2013). Several secretory proteins have been shown to be involved in the pathogenesis of $S$. sclerotiorum, such as an integrin- $\alpha \mathrm{N}$ terminal domain superfamily $S s I T L$, an Rhs repeat-containing protein $S s R h s$, a putative $\mathrm{Ca}^{2+}$ binding EF (elongation factors)hand motif Sscaf1, a $\gamma$-glutamyl transpeptidase $S s G g t 1$, and a cysteine-rich protein SsSSVPI (Guyon et al. 2014; Li et al. 2012; Lyu et al. 2016; Xiao et al. 2014; Yu et al. 2017; Zhu et al. 2013). Here, we identified 93 genes encoding secretory proteins in $S$. sclerotiorum and found that most of them exhibited lower expression levels in lesions of $\mathrm{R} B$. oleracea than in lesions of $\mathrm{S}$ B. oleracea. Except for 14 genes known to be effectors (Guyon et al. 2014; Li et al. 2012; Seifbarghi et al. 2017; Yu et al. 2017), the other 79 genes were newly detected in this study. Correspondingly, 22 receptors were specifically induced in $\mathrm{R} B$. oleracea in the early infection. Except for three kinds of receptors, LRR family proteins, wall-associated kinase-like proteins, and L-type lectin receptors, which were reported up-regulated expressed after inoculation of S. sclerotiorum in B. napus (Wei et al. 2016; Wu et al. 2016; Zhao et al. 2009), we detected several other receptors that were induced in $B$. oleracea, including LysM domain-containing proteins perceived in fungal chitin fragments (Petutschnig et al. 2010; Shinya et al. 2012; Wan et al. 2012), cysteine-rich RLKs, serine/threonine kinase, BRI1-associated receptor kinase, and somatic embryogenesis receptor kinase. However, interactions between receptors and these secretory proteins need to be investigated in more detail in the future. Our findings indicate that the R B. oleracea may effectively perceive and limit the expression of the $S$. sclerotiorum secretory proteins and/or PAMPs by triggering various receptors.

\section{S. sclerotiorum}

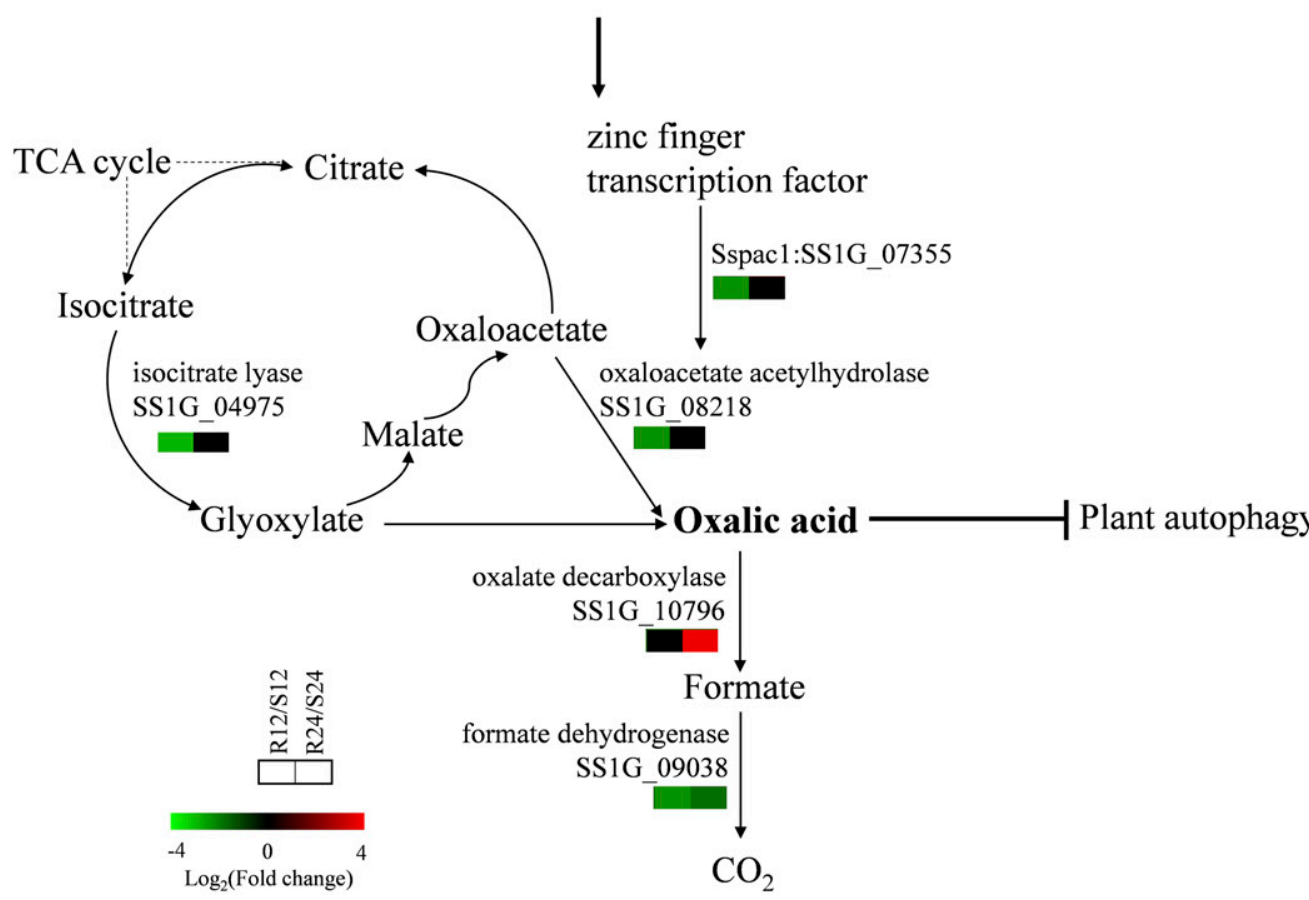

\section{B. oleracea}
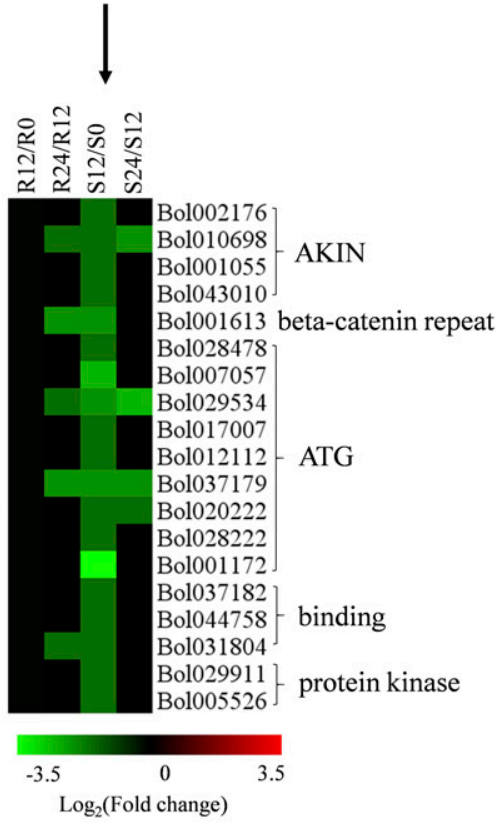

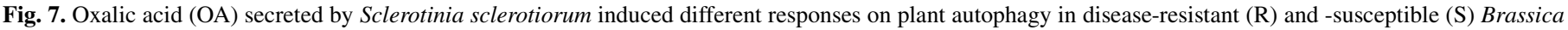
oleracea . TCA = tricarboxylic acid cycle, AKIN = Arabidopsis SNF1 kinase homolog, and ATG = Autophagy. 
WRKY transcription factors are downstream of pathogen perception and regulate resistance genes in the host during infection (Li et al. 2004a, 2004b, 2004c; Tena et al. 2011). In this study, we detected 11 WRKYs and 5 resistance gene likes with specifically up-regulation expression in $\mathrm{R}$ B. oleracea during the early infection. Included in these, three toll-interleukin receptor (TIR) domainencoding genes (Bol024282, Bol018676, and Bol029861) were detected. In the genus Arabidopsis, RLM3 containing a TIR domain was reported to be involved in broad-range immunity to several necrotrophic pathogens (Staal et al. 2008). Wu et al. (2016) also detected up-regulated expression of TIR domain-encoding genes after inoculation of the genus Sclerotinia in resistant B. napus. Among the 11 WRKYs, 2 WRKY50 (Bol012741 and Bol022304), 1 WRKY51 (Bol015902), and 2 WRKY70 (Bol044396 and Bol044275), which are positive modulators of the downstream salicylic acid-mediated signaling (Gao et al. 2010; Li et al. 2004a), were specifically up-regulated in $\mathrm{R} \mathrm{B}$. oleracea. However, these genes show an opposite expression pattern in the inoculated leaves of B. oleracea and B. napus (Mei et al. 2016; Wu et al. 2016). It seems to indicate different responses against $S$. sclerotiorum between stems and leaves.

The fungus expresses genes encoding cell wall-degrading enzymes to break down the cell wall matrix of its host, such as genes that encode the CAZymes to decompose plant pectin, cellulose, and hemicellulose (Amselem et al. 2011; Kars et al. 2005). Conversely, the host expresses genes to biochemically modify the cell wall components and inhibit cell wall degradation (Luna et al. 2011; Vorwerk et al. 2004). PMEIs, PEIs, and GAUTs are key enzymes of pectin metabolism in plants (Caffall et al. 2009; Lionetti et al. 2017). In this study, the processes "carbohydrate metabolic," "pectin catabolic," and pathway "pentose and glucuronate interconversions" were significantly enriched by the SsDEGs-12, which is coincident with the study in B. napus (Seifbarghi et al. 2017), suggesting that these processes possible play roles in the pathogenicity in the early infection. We detected 30 Sclerotinia CAZymes involving in these processes and found that most of them showed lower expression levels in lesions of R B. oleracea, whereas the corresponding genes, such as PMEIs, PEIs, and GAUTs, were specifically up-regulated in $\mathrm{R} B$. oleracea in the early infection. $P M E I$ s and $P E I$ s are regarded as mediators of cell wall integrity maintenance in the plant against fungal, bacterial, and viral pathogens (An et al. 2008; Lionetti et al. 2007, 2014, 2017; Volpi et al. 2011). In the B. napus-S. sclerotiorum pathosystems, PGIPs, but not PMEIs, were the major enzyme inhibitors against Sclerotinia CAZymes (Wu et al. 2016; Zhao et al. 2009). These specifically induced PMEIs and PEIs in this study suggest that $\mathrm{R}$ B. oleracea has a possibly differential Sclerotinia resistance mechanism from $B$. napus to inhibit cell wall degradation. Meanwhile, a series of glycosyl hydrolase, glycoside hydrolase, and glycosyl transferring genes, which are involved in disassembly of the fungal cell wall of $S$. sclerotiorum (Zhuang et al. 2012), were specifically up-regulated in $\mathrm{R} B$. oleracea. These findings seem to indicate that $\mathrm{R} B$. oleracea may disassemble the fungal cell wall during infection.

S. sclerotiorum has long been considered to be a prototypical necrotrophic pathogen (Hegedus and Rimmer 2005). However, recent evidence showed that this fungus may exhibit a brief biotrophic phase in the early infection (Kabbage et al. 2013, 2015; Seifbarghi et al. 2017). Initially, the genus Sclerotinia generates a reducing environment in host cells that suppresses host oxidative burst and calluses deposition, akin to compatible biotrophic pathogens (Kabbage et al. 2013; Williams et al. 2011). After the pathogen is successfully established, $S$. sclerotiorum switches to the necrotic stage to induce the host ROS and programmed cell death to promote hyphal expansion (Hegedus and Rimmer 2005; Kabbage et al. 2013, 2015; Mei et al. 2016). $\mathrm{Ca}^{2+}$ signaling induces the production of ROS via activating the expression of RBOHs in host (Davies et al. 2006; Harding et al. 1997; Keller et al. 1998; Takahashi et al. 2011).
We found that $\mathrm{Ca}^{2+}$ signaling was first induced in $\mathrm{R}$ B. oleracea during 0 to $12 \mathrm{hpi}$ but suppressed during 12 to $24 \mathrm{hpi}$. The earlier accumulation of $\mathrm{H}_{2} \mathrm{O}_{2}$ was subsequently observed in $\mathrm{R}$ B. oleracea at 6 hpi (Fig. 5). These results indicate that the $\mathrm{R} \mathrm{B}$. oleracea produces an oxidative environment to inhibit the establishment of the pathogen in the biotrophic stage and then inhibits the ROS accumulation via suppressing the $\mathrm{Ca}^{2+}$ signaling during necrotic stage. It is consistent with the low expression of Sclerotinia compound appressorium-associated genes and weak establishment of infection cushions in R B. oleracea at 12 hpi (Fig. 4). Taken together, our findings indicate that the resistance $B$. olerace $a$ stems trigger complex strategies to effectively perceive and defend against S. sclerotiorum.

\section{LITERATURE CITED}

Amselem, J., Cuomo, C. A., and van Kan, J. A. 2011. Genomic analysis of the necrotrophic fungal pathogens Sclerotinia sclerotiorum and Botrytis cinerea. PLoS Genet. 7:e1002230.

An, S. H., Sohn, K. H., Choi, H. W., Hwang, I. S., Lee, S. C., and Hwang, B. K. 2008. Pepper pectin methylesterase inhibitor protein CaPMEI1 is required for antifungal activity, basal disease resistance and abiotic stress tolerance. Planta 228:61-78.

Andrade, C. M., Tinoco, M. L., Rieth, A. F., Maia, F. C. O., and Aragão, F. J. L. 2016. Host-induced gene silencing in the necrotrophic fungal pathogen Sclerotinia sclerotiorum. Plant Pathol. 65:626-632.

Arthikala, M.-K., Sánchez-López, R., Nava, N., Santana, O., and Cárdenas, L. 2014. RbohB, a Phaseolus vulgaris NADPH oxidase gene, enhances symbiosome number, bacteroid size, and nitrogen fixation in nodules and impairs mycorrhizal colonization. New Phytol. 202:886-900.

Bashi, Z. D., Rimmer, S. R., Khachatourians, G. G., and Hegedus, D. D. 2012. Factors governing the regulation of Sclerotinia sclerotiorum cutinase A and polygalacturonase 1 during different stages of infection. Can. J. Microbiol. 58:605-616.

Bassham, D. C., Laporte, M., Marty, F., Moriyasu, Y., Ohsumi, Y., Olsen, L. J., and Yoshimoto, K. 2006. Autophagy in development and stress responses of plants. Autophagy 2:2-11.

Bolton, M. D., Thomma, B. P. H. J., and Nelson, B. D. 2006. Sclerotinia sclerotiorum (Lib.) de Bary: Biology and molecular traits of a cosmopolitan pathogen. Mol. Plant Pathol. 7:1-16.

Caffall, K. H., Pattathil, S., Phillips, S. E., Hahn, M. G., and Mohnen, D. 2009. Arabidopsis thaliana T-DNA mutants implicate GAUT genes in the biosynthesis of pectin and xylan in cell walls and seed testa. Mol. Plant 2: 1000-1014.

Cessna, S. G., Sears, V. E., Dickman, M. B., and Low, P. S. 2000. Oxalic acid, a pathogenicity factor for Sclerotinia sclerotiorum, suppresses the oxidative burst of the host plant. Plant Cell 12:2191-2200.

Dangl, J. L., Horvath, D. M., and Staskawicz, B. J. 2013. Pivoting the plant immune system from dissection to deployment. Science 341:746-751.

Davies, D. R., Bindschedler, L. V., Strickland, T. S., and Bolwell, G. P. 2006. Production of reactive oxygen species in Arabidopsis thaliana cell suspension cultures in response to an elicitor from Fusarium oxysporum: Implications for basal resistance. J. Exp. Bot. 57:1817-1827.

Gao, Q. M., Venugopal, S., Navarre, D., and Kachroo, A. 2010. Low oleic acid-derived repression of jasmonic acid-inducible defense responses requires the WRKY50 and WRKY51 proteins. Plant Physiol. 155:464-476.

Garg, H., Li, H., Sivasithamparam, K., Kuo, J., and Barbetti, M. J. 2010. The infection processes of Sclerotinia sclerotiorum in cotyledon tissue of a resistant and a susceptible genotype of Brassica napus. Ann. Bot. 106:897-908.

Guyon, K., Balagué, C., Roby, D., and Raffaele, S. 2014. Secretome analysis reveals effector candidates associated with broad host range necrotrophy in the fungal plant pathogen Sclerotinia sclerotiorum. BMC Genomics 15:336.

Harding, S. A., Oh, S. H., and Roberts, D. M. 1997. Transgenic tobacco expressing a foreign calmodulin gene shows an enhanced production of active oxygen species. EMBO J. 16:1137-1144.

Heard, S., Brown, N. A., and Hammond-Kosack, K. 2015. An interspecies comparative analysis of the predicted secretomes of the necrotrophic plant pathogen Sclerotinia sclerotiorum and Botrytis cinerea. PLoS One 10: e0130534.

Hegedus, D. D., and Rimmer, S. R. 2005. Sclerotinia sclerotiorum: When "to be or not to be" a pathogen? FEMS Microbiol. Lett. 251:177-184.

Joshi, R., Megha, S., Rahman, M., Basu, U., and Kav, N. 2016. A global study of transcriptome dynamics in canola (Brassica napus L.) responsive to Sclerotinia sclerotiorum infection using RNA-Seq. Gene 590:57-67.

Kabbage, M., Williams, B., and Dickman, M. B. 2013. Cell death control: The interplay of apoptosis and autophagy in the pathogenicity of Sclerotinia sclerotiorum. PLoS Pathog 9:e1003287. 
Kabbage, M., Yarden, O., and Dickman, M. B. 2015. Pathogenic attributes of Sclerotinia sclerotiorum: Switching from a biotrophic to necrotrophic lifestyle. Plant Sci. 233:53-60.

Kars, I., Krooshof, G. H., Wagemakers, L., Joosten, R., Benen, J. A., and van Kan, J. A. 2005. Necrotizing activity of five Botrytis cinerea endopolygalacturonases produced in Pichia pastoris. Plant J. 43:213-225.

Kawahara, Y., Oono, Y., Kanamori, H., Matsumoto, T., Itoh, T., and Minami, E. 2012. Simultaneous RNA-Seq analysis of a mixed transcriptome of rice and blast fungus interaction. PLoS One 7:e49423.

Keller, T., Damude, H. G., Werner, D., Doerner, P., Dixon, R. A., and Lamb, C. 1998. A plant homolog of the neutrophil NADPH oxidase gp91 ${ }^{\text {phox }}$ subunit gene encodes a plasma membrane protein with $\mathrm{Ca}^{2+}$ binding motifs. Plant Cell 10:255-266.

Kim, K. S., Min, J. Y., and Dickman, M. B. 2008. Oxalic acid is an elicitor of plant programmed cell death during Sclerotinia sclerotiorum disease development. Mol. Plant-Microbe Interact. 21:605-612.

Li, J., Brader, G., and Palva, E. T. 2004a. The WRKY70 transcription factor: A node of convergence for jasmonate-mediated and salicylate mediated signals in plant defense. Plant Cell 16:319-331.

Li, M., Liang, X., and Rollins, J. A. 2012. Sclerotinia sclerotiorum $\gamma$-glutamyl transpeptidase $(S s-G g t l)$ is required for regulating glutathione accumulation and development of sclerotia and compound appressoria. Mol. PlantMicrobe Interact. 25:412-420.

Li, R., Rimmer, R., Buchwaldt, L., Sharpe, A. G., Séguin-Swartz, G., Coutu, C., and Hegedus, D. D. 2004b. Interaction of Sclerotinia sclerotiorum with a resistant Brassica napus cultivar: Expressed sequence tag analysis identifies genes associated with fungal pathogenesis. Fungal Genet. Biol. 41:735-753.

Li, R., Rimmer, R., Buchwaldt, L., Sharpe, A. G., Séguin-Swartz, G., and Hegedus, D. D. 2004c. Interaction of Sclerotinia sclerotiorum with Brassica napus: Cloning and characterization of endo- and exo-polygalacturonases expressed during saprophytic and parasitic modes. Fungal Genet. Biol. 41: 754-765.

Li, X., Zhang, H., Tian, L., Huang, L., Liu, S., Li, D., and Song, F. 2015. Tomato $\operatorname{SlR} b o h B$, a member of the NADPH oxidase family, is required for disease resistance against Botrytis cinerea and tolerance to drought stress. Front. Plant Sci. 6:463.

Liang, X., Liberti, D., Li, M., Kim, Y. T., Hutchens, A., Wilson, R., and Rollins, J. A. 2015a. Oxaloacetate acetylhydrolase gene mutants of Sclerotinia sclerotiorum do not accumulate oxalic acid but do produce limited lesions on host plants. Mol. Plant Pathol. 16:559-571.

Liang, X., Moomaw, E. W., and Rollins, J. A. 2015b. Fungal oxalate decarboxylase activity contributes to Sclerotinia sclerotiorum early infection by affecting both compound appressoria development and function. Mol. Plant Pathol. 16:825-836.

Lionetti, V., Cervone, F., and Bellincampi, D. 2012. Methyl esterification of pectin plays a role during plant-pathogen interactions and affects plant resistance to diseases. J. Plant Physiol. 169:1623-1630.

Lionetti, V., Fabri, E., De Caroli, M., Hansen, A. R., Willats, W. G., Piro, G., and Bellincampi, D. 2017. Three pectin methylesterase inhibitors protect cell wall integrity for Arabidopsis immunity to Botrytis. Plant Physiol. 173: 1844-1863.

Lionetti, V., Raiola, A., Camardella, L., Giovane, A., Obel, N., Pauly, M., Favaron, F., Cervone, F., and Bellincampi, D. 2007. Overexpression of pectin methylesterase inhibitors in Arabidopsis restricts fungal infection by Botrytis cinerea. Plant Physiol. 143:1871-1880.

Lionetti, V., Raiola, A., Cervone, F., and Bellincampi, D. 2014. Transgenic expression of pectin methylesterase inhibitors limits tobamovirus spread in tobacco and Arabidopsis. Mol. Plant Pathol. 15:265-274.

Lum, G., and Min, X. J. 2011. FunSecKB: The fungal secretome knowledgebase. Database (Oxford) 2011:bar001

Luna, E., Pastor, V., Robert, J., Flors, V., Mauch-Mani, B., and Ton, J. 2011. Callose deposition: A multifaceted plant defense response. Mol. PlantMicrobe Interact. 24:183-193.

Lyu, X., Shen, C., Fu, Y., Xie, J., Jiang, D., Li, G., and Cheng, J. 2016. A small secreted virulence-related protein is essential for the necrotrophic interactions of Sclerotinia sclerotiorum with its host plants. PLoS Pathog 12: e1005435.

Maere, S., Heymans, K., and Kuiper, M. 2005. BiNGO, a Cytoscape plugin to assess overrepresentation of Gene Ontology categories in biological networks. Bioinformatics 21:3448-3449.

Mao, Z., Shi, Y., Cao, Q., Chen, Y., Sun, Y., Liu, Z., Zhang, Q., and Huang, M. 2018. Transcriptional regulation on the gene expression signature in combined allergic rhinitis and asthma syndrome. Epigenomics 10:119-131.

Mei, J., Ding, Y., Li, Y., Tong, C., Du, H., Yu, Y., Wan, H., Xiong, Q., Yu, J., Liu, S., Li, J., and Qian, W. 2016. Transcriptomic comparison between Brassica oleracea and rice (Oryza sativa) reveals diverse modulations on cell death in response to Sclerotinia sclerotiorum. Sci. Rep. 10:34900.

Mei, J., Ding, Y., Lu, K., Wei, D., Liu, Y., Disi, J., Li, J., Liu, L., Liu, S., McKay, J., and Qian, W. 2013. Identification of genomic regions involved in resistance against Sclerotinia sclerotiorum from wild Brassica oleracea. Theor. Appl. Genet. 126:549-556.

Mei, J., Qian, L., Disi, J. O., Yang, X., Li, Q., Li, J., Frauen, M., Cai, D., and Qian, W. 2011. Identification of resistant sources against Sclerotinia sclerotiorum in Brassica species with emphasis on B. oleracea. Euphytica 177: 393-399.

Möller, S., Croning, M. D., and Apweiler, R. 2001. Evaluation of methods for the prediction of membrane spanning regions. Bioinformatics 17:646-653.

Nielsen, H. 2017. Predicting secretory proteins with SignalP. Methods Mol. Biol. 1611:59-73.

Petutschnig, E. K., Jones, A. M. E., Serazetdinova, L., Lipka, U., and Lipka, V. 2010. The lysine motif receptor-like kinase (LysM-RLK) $C E R K 1$ is a major chitin-binding protein in Arabidopsis thaliana and subject to chitin-induced phosphorylation. J. Biol. Chem. 285:2890228911.

Robinson, M. D., McCarthy, D. J., and Smyth, G. K. 2010. edgeR: A Bioconductor package for differential expression analysis of digital gene expression data. Bioinformatics 26:139-140.

Rollins, J. A. 2003. The Sclerotinia sclerotiorum pacl gene is required for sclerotial development and virulence. Mol. Plant-Microbe Interact. 16: 785-795.

Saharan, G. S., and Mehta, N. 2008. Sclerotinia Diseases of Crop Plants: Biology, Ecology and Disease Management. Springer, Dordrecht, The Netherlands.

Seifbarghi, S., Borhan, M. H., Wei, Y., Coutu, C., Robinson, S. J., and Hegedus, D. D. 2017. Changes in the Sclerotinia sclerotiorum transcriptome during infection of Brassica napus. BMC Genomics 18:266.

Shinya, T., Motoyama, N., Ikeda, A., Wada, M., Kamiya, K., Hayafune, M., Kaku, H., and Shibuya, N. 2012. Functional characterization of CEBiP and CERK1 homologs in Arabidopsis and rice reveals the presence of different chitin receptor systems in plants. Plant Cell Physiol. 53: 1696-1706.

Staal, J., Kaliff, M., Dewaele, E., Persson, M., and Dixelius, C. 2008. RLM3, a TIR domain encoding gene involved in broad-range immunity of Arabidopsis to necrotrophic fungal pathogens. Plant J. 55:188-200.

Takahashi, F., Mizoguchi, T., Yoshida, R., Ichimura, K., and Shinozaki, K. 2011. Calmodulin-dependent activation of MAP kinase for ROS homeostasis in Arabidopsis. Mol. Cell 41:649-660.

Tena, G., Boudsocq, M., and Sheen, J. 2011. Protein kinase signaling networks in plant innate immunity. Curr. Opin. Plant Biol. 14:519-529.

Volpi, C., Janni, M., Lionetti, V., Bellincampi, D., Favaron, F., and D’Ovidio, R. 2011. The ectopic expression of a pectin methyl esterase inhibitor increases pectin methyl esterification and limits fungal diseases in wheat. Mol. Plant-Microbe Interact. 24:1012-1019.

Vorwerk, S., Somerville, S., and Somerville, C. 2004. The role of plant cell wall polysaccharide composition in disease resistance. Trends Plant Sci. 9: 203-209.

Wan, J., Tanaka, K., Zhang, X. C., Son, G. H., Brechenmacher, L., Nguyen, T. H. N., and Stacey, G. 2012. LYK4, a lysin motif receptor-like kinase, is important for chitin signaling and plant innate immunity in Arabidopsis. Plant Physiol. 160:396-406.

Wang, C., Yao, J., Du, X., Zhang, Y., Sun, Y., Rollins, J. A., and Mou, Z. 2015. The Arabidopsis mediator complex subunit16 is a key component of basal resistance against the necrotrophic fungal pathogen Sclerotinia sclerotiorum. Plant Physiol. 169:856-872.

Wang, L., Feng, Z., Wang, X., Wang, X., and Zhang, X. 2010. DEGseq: An R package for identifying differentially expressed genes from RNA-seq data. Bioinformatics 26:136-138.

Wei, L., Jian, H., Lu, K., Filardo, F., Yin, N., Liu, L., Qu, C., Li, W., Du, H., and $\mathrm{Li}$, J. 2016. Genome-wide association analysis and differential expression analysis of resistance to Sclerotinia stem rot in Brassica napus. Plant Biotechnol. J. 14:1368-1380.

Westermann, A. J., Gorski, S., and Vogel, J. 2012. Dual RNA-seq of pathogen and host. Nat. Rev. Microbiol. 10:618-630.

Williams, B., Kabbage, M., Kim, H. J., Britt, R., and Dickman, M. B. 2011. Tipping the balance: Sclerotinia sclerotiorum secreted oxalic acid suppresses host defenses by manipulating the host redox environment. PLoS Pathog 7:e1002107.

Wirthmueller, L., Maqbool, A., and Banfield, M. J. 2013. On the front line: Structural insights into plant-pathogen interactions. Nat. Rev. Microbiol. 11:761-776.

Wu, J., Zhao, Q., Yang, Q., Liu, H., Li, Q., Yi, X., Cheng, Y., Guo, L., Fan, C., and Zhou, Y. 2016. Comparative transcriptomic analysis uncovers the complex genetic network for resistance to Sclerotinia sclerotiorum in Brassica napus. Sci. Rep. 8:19007.

Xiao, X., Xie, J., Cheng, J., Li, G., Yi, X., Jiang, D., and Fu, Y. 2014. Novel secretory protein Ss-Caf1 of the plant-pathogenic fungus Sclerotinia sclerotiorum is required for host penetration and normal Sclerotia development. Mol. Plant-Microbe Interact. 27:40-55. 
Yamaguchi, K., Mezaki, H., Fujiwara, M., Hara, Y, and Kawasaki, T. 2017. Arabidopsis ubiquitin ligase PUB12 interacts with and negatively regulates Chitin Elicitor Receptor Kinase 1 (CERK1). PLoS One 12:e0188886.

Yang, B., Srivastavaa, S., Michael, K. D., and Nat, N. V. K. 2007. Transcriptional profiling of canola (Brassica napus L.) responses to the fungal pathogen Sclerotinia sclerotiorum. Plant Sci. 173:156-171.

Yang, G., Tang, L., Gong, Y., Xie, J., Fu, Y., Jiang, D., Li, G., Collinge, D. B., Chen, W., and Cheng, J. 2018. A cerato-platanin protein $S s C P 1$ targets plant PRI and contributes to virulence of Sclerotinia sclerotiorum. New Phytol. 217:739-755.

Yazawa, T., Kawahigashi, H., Matsumoto, T., and Mizuno, H. 2013. Simultaneous transcriptome analysis of sorghum and Bipolaris sorghicola by using RNA-seq in combination with de novo transcriptome assembly. PLoS One 8:e62460.

Yu, Y., Xiao, J., Zhu, W., Yang, Y., Mei, J., Bi, C., Qian, W., Qing, L., and Tan, W. 2017. Ss-Rhs1, a secretory Rhs repeat-containing protein, is required for the virulence of Sclerotinia sclerotiorum. Mol. Plant Pathol. 18: 1052-1061.
Zhao, J., Buchwaldt, L., Rimmer, S. R., Sharpe, A., McGregor, L., Bekkaoui, D., and Hegedus, D. 2009. Patterns of differential gene expression in Brassica napus cultivars infected with Sclerotinia sclerotiorum. Mol. Plant Pathol. 10:635-649.

Zhao, J., Udall, J. A., Quijada, P. A., Grau, C. R., Meng, J., and Osborn, T. C. 2006. Quantitative trait loci for resistance to Sclerotinia sclerotiorum and its association with a homeologous non-reciprocal transposition in Brassica napus L. Theor. Appl. Genet. 112:509-516.

Zhao, J., Wang, J., An, L., Doerge, R. W., Chen, Z., Grau, C. R., Meng, J., and Osborn, T. C. 2007. Analysis of gene expression profiles in response to Sclerotinia sclerotiorum in Brassica napus. Planta 227:13-24.

Zhu, W., Wei, W., Fu, Y., Cheng, J., Xie, J., Li, G., Yi, X., Kang, Z., Dickman, M., and Jiang, D. 2013. A secretory protein of necrotrophic fungus Sclerotinia sclerotiorum that suppresses host resistance. PLoS One 8:e53901.

Zhuang, X., McPhee, K., Coram, T., Peever, T., and Chilvers, M. 2012. Rapid transcriptome characterization and parsing of sequences in a non-model host-pathogen interaction: Pea-Sclerotinia sclerotiorum. BMC Genomics 13:668. 